\title{
Subtitling and its Acceptability in the Film Farewell, My Concubine: A Multimodal Approach
}

\author{
Nan Wang* \\ School of Foreign Languages, Hunan University, Lushannan Road, Yuelu District, Changsha, Hunan Province, China \\ Corresponding Author: Nan Wang, E-mail:wangnanhu@hnu.edu.c
}

\section{ARTICLE INFO}

Article history

Received: September 19, 2019

Accepted: November 05, 2019

Published:December 31, 2019

Volume: 10 Issue: 6

Advance access: December, 2019

Conflicts of interest: None

Funding: None

Key words:

Subtitling,

Farewell, My Concubine,

Multimodality,

Multimodal Transcription,

Intersemiotic Complementarity

\begin{abstract}
Subtitling is intersemiotic translation that can bridge differences between two languages and should consider semiotic modes as subtitling is not merely determined by the source text but also by the constraints of time and space. The rapid development of audiovisual translation from the perspective of multimodality facilitates the development of translation. However, few studies focus on the rationality of subtitling methods. Farewell, My Concubine is a famous Chinese film with its subtitles translated by Linda Jaivin, an Australian audiovisual translator. Her subtitles contribute to the award of the Golden Palm Award at the 1993 Cannes Film Festival. Under spatial-temporal constraints, multimodal transcription provides a basis for meaning choices to discuss how to choose proper translation methods guided by semiotic modes. The translation methods adopted in Farewell, My Concubine can be explicated such as adaptation, amplification, non-translation, and deduction including condensation, reductive paraphrasing and deletion. The acceptability of Jaivin's translation methods can be explored from ideational intersemiotic complementarity that centers on multimodal consonance between verbal and visual modes to see how semiotic modes complement each other especially when Jaivin has altered the source text. The applicability of intersemiotic complementarity creatively finds a new way to discuss the relations between frames and subtitles. Meanwhile, the multimodal approach indicates now the interdisciplinary study on subtitling is a must and a trend to explore both the translation methods and their acceptability. It is also found that there are still complementary relations between non-verbal modes and translated subtitles. These findings prove the subtitling methods acceptable and the role of multimodality in subtitling essential. Translation cannot entirely replicate the original text, and different translators may adopt the same translation methods while they will produce varied translated text. In this respect, the analysis of translation methods and their rationality is of universality. Furthermore, the study on subtitles will promote the film itself and the culture of the country.
\end{abstract}

\section{INTRODUCTION}

Scientific and technological progress drives the progress of multimodal products like advertisements printed, TV advertisements, cartoons, movies, musicals, and the like. Accordingly, the methods to preserve these products have been upgraded. So, these culture-bound multimodal products can serve as a tool for intercultural exchanges. When language differs in various culture, translation is a channel that can bridge differences between two languages. Jakobson (1959) classifies the translation into "intralingual translation", "interlingual translation" and "intersemiotic translation", which respectively correspond to "rewording", "translation proper" and "transmutation". As many advanced scientific instruments have been used such as computers, video recorders, smart phones, multimodality has ever-increasingly become a research hotspot especially in overseas studies.

How to translate from the perspective of multimodality is intriguing and challenging. Though some scholars have realized the importance of semiotic modes in translation, they seldom delve into the semiotic landscape as they "normally specialize in the transfer of verbal texts, and because of multimodal design of texts, they have to work with other experts like photographers, composers, graphic designers, etc." (Kaindl, 2013:258). In addition, the interplay of semiotic modes means that the relations between subtitles and non-verbal modes are complex and sometimes are difficult to make a precise judgement. Martinec (2005) once discussed the relations between image and text, developing a framework including the status of image and text (equal/unequal), and logico-semantic relations (elaboration, extension and enhancement) based on Halliday's Systemic Functional Grammar (SFG) (2014). It is a complex framework and the status and the logico-semantic relations overlap to form a new relation. Subtitling entails the involvement of semiotic modes to prune the information that can be garnered from visual or acoustic modes. Moreover, with the guidance of semiotic modes, some information can be amplified and adapted to make it easier to understand the information concealed in the visual and acoustic modes. Given the factor of multimodality, some translation strategies used have changed the source text a lot. Then the relations between the verbal modes and non-verbal modes also alter. 
The paper will analyze the subtitles of the film Farewell, My Concubine (Note 1), a famous movie in the history of Chinese films. The subtitle translator of the film is Linda Jaivin, an Australian audiovisual translator. The paper is going to discuss how semiotic modes contribute to meaning-making, those modes which in turn help choose the proper subtitling strategies. Then, this study tends to prove the acceptability of the author's methods of translating subtitles. Each method is not so much the result of language analysis as on the basis of multimodal analysis, for each choice has its meaning. The paper tends to answer the questions as follows:

1) Why should the audiovisual translation be studied from the perspective of multimodality?

2) How can the translation methods in the film Farewell, My Concubine be analyzed from the perspective of multimodality?

3) How can these methods be proved acceptable from the perspective of multimodality?

\section{LITERATURE REVIEW}

Western scholars first focus on audiovisual translation as a result of economic, political and cultural development. According to Taylor (2015) and Gambier (2013), subtitle translation is a part of audiovisual translation that also encompasses intralingual subtitling, live subtitling, audio transcription script/scenario translation, interlingual subtitling, dubbing, free commentary, voice-over, surtitling. Dollerup (1974) stressed the significance of subtitles in English learning. Leading figures with significant research results in audiovisual translation in the West include Yves Gambier, Jorge Diaz-Cintas, Henrik Gottlieb, Karamitroglou, etc.

Many scholars have studied the subtitling from the perspective of multimodality. Chaume (2004) calls for an interdisciplinary approach in audiovisual translation. Taylor $(2003,2004,2016)$ takes a lead in analyzing interlingual subtitle translation based on multimodal transcription proposed by Thibault (2000) and Anthony Baldry (2004). Pettit (2004) studies different audiovisual genres to exploit the influence of multimodality upon interlingual translation, intending to answer the relations between subtitle, soundtrack and image, the impacts of culture-specific verbal and visual features on translators, the non-verbal impacts and the impacts of genres on translation. Chuang (2006) introduces the concept of the distributions of the modes, which means different modes can be transformed to each other such as spoken modes to written ones, other semiotic modes to written ones, and spoken to other semiotic ones.

Some scholars turn their attention to the translation discipline construction. Gambier (2006) deems that some revisions in the conceptions related to translation study are necessary like the notion of text, the concept of sense and translation, translation units, translation norms and the like when these concepts are discussed in audiovisual translation. Kaindl (2013) proposes two different concepts: intramodal translation and intermodal translation, intramedial translation and intermedial translation given the mode and the medium. Leontovich (2019) believes film translation was "adaptation", and intersemiotic translation can be seen as "transposition" and "resemiotisation". He proposes "de-centering of language" in the semiotic landscape, that is, due attention should be paid to semiotic modes.

These studies, comprehensive and detailed, reveal the rapid development of audiovisual translation from the perspective of multimodality which also facilitates the development of translation. These scholars give priority to the role of multimodal social semiotics in translating. Some studies attach importance to the accessibility of information for the disabled. Aware of the importance of multimodality, these scholars concentrate on the interplay mechanisms for semiotic modes and apply these mechanisms into practice to testify their validity.

However, few studies concentrate on subtitling methods adopted in famous Chinese films in terms of multimodal transcription, especially when the translator is not Chinese. The subtitles added serve as a new verbal mode which is by no means equivalent to the original one though translators may strive to imitate the original features and retain the original information. In this aspect, the interplay of the original subtitles, visual modes and acoustic modes does not equate to the combination of the translated subtitles, visual modes and acoustic modes. Furthermore, few analyses present the acceptability of the adopted translation methods in terms of intersemiotic complementarity.

\section{DATA}

\section{Farewell, My Concubine}

Farewell, My Concubine is a Chinese blockbuster directed by Chen Kaige, a Chinese director who was awarded the 22nd Golden Rooster Award for Best Directing. The masterpiece is the only film in China that wins the Golden Palm Award at the 1993 Cannes Film Festival. Concubine is the representative work of Chen as "it is fair to say that before Concubine, Chen had not found a popular form that would communicate with a broad audience" (Lau, 1995: 19). The film builds on Lilian Lee' work of the same name Farewell, My Concubine. "Chen's biggest adaptation of Lee's masterpiece ends with a scene of Dieyi's suicide. The adaptation makes the film more storytelling and enjoyable, and meanwhile leaves a meaningful space for interpretation and analysis" (Shi, 2018: 180). The film narrates a story about Cheng Dieyi (also known as Douzi). The masterpiece involves four parts: seeking art, learning opera, performing opera and die for art through which is the "interplay of several major binaries: art (dream/unreality) versus life (material/reality), loyalty versus betrayal, female versus male" (Lau, 1995: 23).

Zhou (2011: 163) stated: "what Concubine tells more than the story of actors. It more shows the complexity of human nature and the adversity of destiny against the backdrop of profound Chinese culture and complicated historical contexts. The film fills with humanitarian compassion." The film not only narrates Dieyi's love for art and Xiaolou, but also the vicissitudes of opera. 


\section{Main Characters in the Film}

Dieyi, Xiaolou and Juxian are three main characters in the film. Dieyi loved his stage brother Xiaolou in the way just like Concubine Yu that Dieyi was enacted loved her King of Chu who failed and suicided when fighting against Liu Bang (256 B.C. - 195 B.C.). Dieyi was too obsessed by his role in the opera to notice his change in gender conception. To some extent, he was a "woman" and craved the role of Concubine Yu because he could be Xiaolou's concubine merely in the opera. Dieyi was a "real Concubine Yu" but a tragedy because he could not follow the trend of times. Thus, Dieyi ended up with suicide as Concubine Yu did after seeing right through reality that he was out of the place in that society. His devotion to the art and his love for Xiaolou went nowhere. Dieyi's death indicated that he eventually realized his gender identity and that he was not identical with Concubine Yu.

Xiaolou acted as the King of Chu and was Juxian's husband and Dieyi's stage brother. In the film, he had smashed bricks for three times. When he was a child, he did so to help his master out of trouble. He helped Juxian by smashing the teapot by his heads. The last time happened when he was asked to smash the brick in the process of interrogation. The behavior of the first two times reflects his bravery and justice. However, oppressed by the cultural revolution and coerced by the red guards, he "confided" everything and "negated" everything meanwhile. In this aspect, he was timid, overcautious, pliable and wretched. His changes show his compromise with the society and that he is a false "King of Chu".

Juxian was once a well-known prostitute and then became a good wife. Juxian is clever and sophisticated. She "forced" Xiaolou to marry her. Then, she "forced" Dieyi to keep away from her husband by cheating him in exchange for saving Dieyi's life. However, Juxian is kind-hearted. She understood Diyi, a rival in love. She, behaving like a mother, took good care of Dieyi when he rehabilitated from drug abuse. When abused in the cultural revolution, she silently bore all hardships and eventually hung herself. Her life is also a tragedy because she could not triumph over her destiny though she had endeavored to break with the past. The fate in store for her was Xiaolou's betray as he denied his love for her when he was criticized by the red guards. She died with her dream of becoming an ordinary wife that could even not be tolerated by society due to her former identity.

\section{Linda Jaivin, the Translator}

The subtitles of the blockbuster Farewell, My Concubine were translated by Linda Jaivin, an Australian audiovisual translator. She is also a writer and a sinologist, whose Chinese name is “贾佩琳” (Jia Peilin). She seems to witness the development of Chinese movies as she has subtitled many Chinese movies from Farewell, My Concubine to Forever Enthralled (《梅兰芳》), and from Devils on the Doorstep (《鬼子来了》) to Lifetimes Living (《活着》). In this aspect, she serves as "the pushing hands to introduce Chinese movies to the world" (Jin, 2013: 65). Her subtitling for the movie is also one of the reasons that Concubine could win the Palme d'Or at the 1993 Cannes Film Festival.

\section{THEORETICAL BASIS}

Multimodal transcription can be utilized to analyze subtitling methods. Then, ideational intersemiotic complementarity put forward by Royce $(2002,2007,2015)$ is used to analyze the acceptability of these strategies. If there is any lexical cohesion based on Halliday's SFG, the visual elements and subtitles are complementary. Then, the translation methods are advisable in line with spatial-temporal constraints and audiovisual requirements that the subtitles be easy to read and understand.

\section{Multimodal Transcription}

Multimodal transcription, improved by Taylor (2003, 2004, 2016), provides a basis for meaning choices under the spatial-temporal constraints. There the paper analyzes as following procedures, some of which have been simplified as multimodal transcription is "time-consuming and not commercially viable on a cost-benefit basis" (Taylor, 2003: 191) to make the analysis more accessible and convenient for both target readers and the author:

1) the visual frame;

2) the components of the visual images captured by screenshots: CP (camera position), HP (horizontal perspective), VP (vertical perspective), VF (visual focus, like gaze vectors), D (the virtual distance of the shot), VS (visually salient items), VC (visual collocation, the secondary items that are visible on screen and which provide some meaningful content), CR (the color used), $\mathrm{CO}$ (coding orientation, describing whether the scene is natural or surreal);

3) the kinetic action of participants, like facial gestures, body movement;

4) the complete soundtrack, like dialogue, music, sound, etc. (Taylor, 2003: 192)

Multimodal transcription is designed to "provide insights into how meaning is 'made'... via the combination of various semiotic modalities, and thus how the verbal message interacts with other meaning resources" (Taylor, 2003: 194).

\section{Ideational Intersemiotic Complementarity}

Interemiotic complementarity is based on Halliday's SFG that views language as "social semiotics". Royce's theory is designed to explicate "the nature of the intersemiotic semantic relationship between the visual and verbal modes, to explain just what features make multimodal text visual-verbally coherent" (Royce, 2007: 63). Thus, intersemiotic complementarity tends to focus on multimodal consonance between verbal and visual modes to see how these modes complement each other. Based on ideational, interactive and compositional metafunction in SFG, Royce's theory of intersemiotic complementarity have three dimensions: Ideational, Interpersonal and Compositional Intersemiotic Complementarity.

To examine how the visual and verbal modes interact intersemiotically in ideational dimension, first, we should proceed from the visual modes to identify the represented 
participants, the processes or the activity, the circumstances and attributes. These identified elements can be regarded as the Visual Message Elements (VMEs). These elements are made by sign-producers by using necessary techniques. "These elements are visual features which carry semantic properties" (ibid.: 70). Second, based on these VMEs, we should examine the verbal elements that are semantically related to these VMEs. Then, the verbal elements and VMEs will be analyzed in terms of the cohesion. The types of lexical relation are listed in Table 1. If the analysis of VEMs and verbal elements indicates the cohesion, then it can be argued that there is intersemiotic complementarity between visual modes and verbal modes.

Royce's Ideational Intersemiotic Complementarity finds a new way to discuss the relations between images and languages, and creatively integrates Halliday's lexical with social semiotics, which expands the fields of SFG's application. Some concepts and terminologies in the linguistic realm have been wielded to analyze how multimodality interacts. Royce's theory "has applied and extended the Systemic Functional Linguistic concept of metafunctions to multimodality in text" (Royce, 2007: 104). Royce has analyzed the TESOL classroom (2002), the magazine The Economist (2007) and legal cartoons (2015). Constantly enriching his theory and theory's application, he has focused on intersemiotic dissonance. Moreover, his theory is applied to analyze Chinese tourist entry tickets (Bowcher, 2013). Zhu (2007) once pinpointed the disadvantage of multimodal discourse analysis and he believed the interplay and the complementarity of multimodalities cannot be ascertained. However, Royce's theory provides a new perspective for the analysis of intersemiotic interplay.

\section{SUBTITLES ANALYSIS FROM THE PERSPECTIVE OF MULTIMODALITY}

"Screen texts are short-lived and do not fit readily into the traditional dichotomy between Source Text and Target Text. They are also distinctive in that they are multimodal" (Gambier, 2006: 3). Thus, the multimodal text determines that its translation should take visual modes and acoustic modes into consideration for the sake of conciseness and understandability. Strictly speaking, no text is monomodal given its font, size, position, etc. When translators subtitle, some

Table 1. Types of lexical relation and Definition (ibid.: 68)

\begin{tabular}{|c|c|}
\hline Types of lexical relation & Definition \\
\hline Repetition & $\begin{array}{l}\text { The repetition of experiential } \\
\text { meaning }\end{array}$ \\
\hline Synonymy & A similar experiential meaning \\
\hline Antonymy & An opposite experiential meaning \\
\hline Meronymy & $\begin{array}{l}\text { The classification of a general } \\
\text { class of something and its } \\
\text { subclasses }\end{array}$ \\
\hline Hyponymy & $\begin{array}{l}\text { Reference to the whole of } \\
\text { something and its constituent parts }\end{array}$ \\
\hline Collocation & $\begin{array}{l}\text { The words that tend to cooccur in } \\
\text { various subject areas }\end{array}$ \\
\hline
\end{tabular}

information is added or adapted while some is deleted as the translator "can choose to ignore those meanings that are represented in other semiotic modes" (Chuang, 2006: 375) instead of retaining everything in the dialogues.

Subtitling is distinctive as it faces spatial-temporal constraints while meanwhile must meet the audiences' needs that they can easily gain the information from subtitles without having a negative impact on non-verbal modes. On the other hand, multimodality is by no means a constraint on translation but serves an effective tool to figure out what is to be deducted, added or transformed. As the translator wrestles with verbal and non-verbal information, he should focus on "meanings openly expressed and others inferred by more subtle forms of communication; a rise in intonation, a gesture accompanying the utterance" (Pettit, 2004: 25).

According to Leontovish (2019: 407), a text concerning semiotic system is connected with such transformations as 1) reduction - omission of parts of the original; 2) extensionaddition, filling in the blanks, and signifying the unsaid; 3 ) reinterpretation-modification or remodeling of the original in accordance with the director's creative ideas. In the film Farewell, My Concubine, there is a distinctive strategy adopted by Jaivin, that is, non-translation. Non-translation is used not because there are the syntactic differences between source text (ST) and target text (TT) but because the translator purposely does it. The "non-translation" appears for more than once in several scenes related to operas. It is necessary to discuss the reasons for "non-translation" from the perspective of multimodality.

\section{Deduction}

Spatial-temporal constraints require that subtitling take time and space into consideration, or otherwise subtitling accounts to screenplay translation which can be translated as detailed as possible. Thus, deduction is an indispensable strategy in subtitling. According to Li (2001: 39), deduction can be divided into three categories: condensation, reductive paraphrasing and deletion; condensation means core information should be retained; reductive paraphrasing indicates the original meaning should be rendered in a succinct manner; deletion is the complete omission of the information.

Dieyi was disappointed about Juxian's betray as she had promised to leave Xiaolou after he saved Xiaolou from the Japanese. The close shot of the last frame is thought-provoking when the previous medium-short short turns into a close shot that indicates an intimate social distance. The absence of gaze "offers the represented participants to the viewer as items of information, objects of contemplation..." (Kress and van Leeuwen, 2006: 119). Dieyi's disappointment partly results from the fact that he is too indulgent in the role, the concubine in the opera, to come to reality. Jaivin noticed what the servants did was a dish also named "farewell, my concubine" which is made of a soft-shelled turtle and a chicken. The dish is to commemorate the king of Chu and his concubine Yu. The allusion "farewell, my concubine" arguably tells a story that the King of Chu bid farewell to his concubine when he was defeat by Liu Bang. However, in the frames in Table 2, the turtle symbolizing departure (Note 2) was killed at the presence of Dieyi, 
Example 1

\begin{tabular}{ll}
\hline Frame \\
ST \\
$\mathrm{TT}$ & I think this opera, Farewell, My Concubine, has turned into Farewell, My King \\
\hline
\end{tabular}

Table 2. Multimodal transcription of Example 1

\begin{tabular}{|c|c|c|c|c|}
\hline Visual frame & Visual image & Kinetic action & Soundtrack & Subtitles \\
\hline & $\begin{array}{l}\text { CP static } \\
\text { HP frontal } \\
\text { VP eye-level } \\
\text { D medium } \\
\text { VS soft-shelled turtle \& bronze } \\
\text { phoenix } \\
\text { VC the two servants } \\
\text { VF looking at the turtle } \\
\text { CO natural }\end{array}$ & $\begin{array}{l}\text { The two } \\
\text { servants killing } \\
\text { the turtle with } \\
\text { a silver utensil } \\
\text { collecting its } \\
\text { bleed }\end{array}$ & $\begin{array}{l}\text { Dropping water; } \\
\text { instrument; cutting noise }\end{array}$ & \\
\hline & $\begin{array}{l}\text { CP moving } \\
\text { HP oblique } \\
\text { D medium-long } \\
\text { VS Yuan Shiqin } \\
\text { VC the two servants } \\
\text { VF the servants looking at Yuan }\end{array}$ & Yuan standing & 这就是霸王别姬 & $\begin{array}{l}\text { I think this opera, } \\
\text { Farewell, My } \\
\text { Concubine... }\end{array}$ \\
\hline & $\begin{array}{l}\text { CP moving } \\
\text { HP frontal } \\
\text { D medium } \\
\text { VS Yuan } \\
\text { VC Dieyi }\end{array}$ & $\begin{array}{l}\text { Yuan swiveling } \\
\text { around the table }\end{array}$ & 依我之见 & has turned into... \\
\hline & VF Yuan looking at the dish & $\begin{array}{l}\text { Yuan coming } \\
\text { closer to Dieyi }\end{array}$ & $\begin{array}{l}\text { 你们这戏演到这份上 竟 } \\
\text { 成了姬别霸王 }\end{array}$ & Farewell, My King \\
\hline & $\begin{array}{l}\text { D: close } \\
\text { VF: no gaze } \\
\text { HP: frontal } \\
\text { VS: Dieyi }\end{array}$ & $\begin{array}{l}\text { Dieyi } \\
\text { contemplating }\end{array}$ & $\begin{array}{l}\text { 你们这戏演到这份上 竟 } \\
\text { 成了姬别霸王 }\end{array}$ & Farewell, My King \\
\hline
\end{tabular}

the reincarnation of concubine Yu. Thus, the core information related to Xiaolou's internal feelings is retained by using the pun. Hearing what Yuan said, Dieyi tried to smile. He understood Yuan's illocutionary meaning. In this scene, the dish matters little but the pun wielded by Yuan to amuse Dieyi matters a lot. Therefore, Javin's translation retains the core information.

This scene is featured by the soundtrack as it has not only the dialogue and the click but the sound representing a new era like the automobile noise, and the music broadcast Ode to the motherland which is released in 1951 after the founding of People Republic of China in 1949. Besides, what Xiaosi and Dieyi wear is different from that in the past. The visual modes and acoustic modes all symbolize a new era. When Xiaosi who was influenced by new ideas of the new era would like to leave, Dieyi was furious. Xiaosi, Dieyi's disciple and adopted "son", left first and then came back when
Xiaosi heard "Be a bit player your whole life". Xiaosi looked fierce. He leisurely came close to his master, and arrogantly addresses Dieyi as "Mister Chen". In this new society, Xiaosi was definitely different from his master who was influenced by the old educational methods and the way to become a well-known actor. Xiaosi's roar denounced his rupture with his master and the so-called benighted old society. The frontal angle indicates "what you see here is part of our world, something we involved in" (Kress and van Leeuwen, 2006: 136). The viewers are involved with the represented participants, and this can herald the decline of the opera. The translated version emphasizes the outcome and the verbal element "Old Society" that cannot be easily detected in visual mode. Consequently, the information "Old Society" is saved.

In Table 4, the costume of Douzi presents his role in the opera — "Dan" that acts as a female figure. Na Kun, the 
manager, thought highly of Douzi for his nice little figure. The close shot showing the head and shoulder of the represented participant clearly shows the pretty countenance as if Douzi was singing for all viewers. An intimate relationship is established between viewers and Douzi. Then Na Kun raised a question to see if Douzi was able to perform for his client, Eunuch Zhang. Na Kun himself was not a layman because he could discern the role that Douzi played and he also knew the difficulties in performing Dreaming of the World Outside the Nunnery. The sinologist Jaivin also notices the costume mode that represents the role of Douzi, so she deletes a part of the original information that is irrelevant to the scene. The superlative "hardest" responses to the anxious expressions of Douzi's stage brothers. What's more, Douzi had not changed his gender awareness as he knowingly mis-recited the lyrics related to his gender several times. The opera Nunnery itself is challenging to say nothing of gender conversion for a teenage boy. The visual mode assists in omitting some information which will be too wordy to enjoy the film itself.

Example 2

\begin{tabular}{ll}
\hline Frame \\
ST
\end{tabular}

\section{Adaptation}

Adaptation is "a continuum of interventional strategies ranging from making minor changes to significant ones" (Tang, 2014: 441). Taylor (2015: 170) believes that "audiovisual translation (AVT) can be seen as giving all audiences access to foreign language products through adaptation for such methods as dubbing, subtitling, surtitling, voiceover, simultaneous translation, real-time subtitling and the like". Adaptation is a kind of reinterpretation in the light of translators' subjectivity, that is, the translator's understanding of visual and acoustic modes affects the process of meaning choices. In other words, audiovisual translators based on the semiotic resources intervene in language resources which add or delete information to the original subtitles. Sometimes, what determines subtitle translators' choices of adaptation is not the verbal information but instead, the non-verbal information which suggests "what the speaker truly means, changing the denotative meaning of the original, sometimes leads the subtitler and dubber to alter their translations appropriately" (Pettit, 2004: 37). At this moment the original implicit meanings are no longer implied.

Dramatic conflicts appear in Figure 1 successively. Dieyi was rudely interrupted by the lay audiences most of which were the wounded of Kuomintang. Xiaolou managed to address the turmoil but was assaulted by the soldiers. His pregnant wife, Juxian, wanted to save him but was attacked to miscarriage. Dieyi was arrested for a groundless charge. Hardly did Xiaolou rushed out when he heard he lost his child. In frame 2, the visual silence is the suffering Juxian, which signifies her importance to Xiaolou. In frame 3,

Table 3. Multimodal transcription of Example 2

\begin{tabular}{|c|c|c|c|c|}
\hline Visual frame & Visual image & Kinetic action & Soundtrack & Subtitle \\
\hline & $\begin{array}{l}\text { CP static } \\
\text { HP oblique } \\
\text { D long } \\
\text { VS Dieyi } \\
\text { VF Dieyi looking at the door }\end{array}$ & Dieyi shouting & $\begin{array}{l}\text { Click; } \\
\text { Music: } \\
\text { Ode to the motherland } \\
\text { automobile noise; } \\
\text { 滚吧! 一辈子跑你的龙 } \\
\text { 套去吧 }\end{array}$ & $\begin{array}{l}\text { Go, then! Be a bit player } \\
\text { your whole life! }\end{array}$ \\
\hline & $\begin{array}{l}\text { CP moving } \\
\text { VS Xiaosi } \\
\text { VF Xiaosi looking at Dieyi }\end{array}$ & Xiaosi coming back & $\begin{array}{l}\text { Music: } \\
\text { Ode to the motherland }\end{array}$ & \\
\hline & CP static & $\begin{array}{l}\text { Xiaosi shifing his } \\
\text { head }\end{array}$ & $\begin{array}{l}\text { Music: Ode to the } \\
\text { motherland } \\
\text { 程老板... }\end{array}$ & Mister Cheng... \\
\hline & VF Xiaosi looking at Dieyi & $\begin{array}{l}\text { Xiaosi walking a } \\
\text { little closer; }\end{array}$ & $\begin{array}{l}\text { Music: Ode to the } \\
\text { motherland } \\
\text { 您这话要搁在旧社会 } \\
\text { 我信 }\end{array}$ & I can hardly believe this \\
\hline & $\begin{array}{l}\text { CP static } \\
\text { VF Xiaosi looking at Dieyi } \\
\text { HP frontal }\end{array}$ & $\begin{array}{l}\text { Xiaosi having the } \\
\text { bag on his back }\end{array}$ & $\begin{array}{l}\text { Music: Ode to the } \\
\text { motherland } \\
\text { 在新社会说, 我不信 }\end{array}$ & $\begin{array}{l}\text { It's like something out of } \\
\text { the old Society }\end{array}$ \\
\hline
\end{tabular}




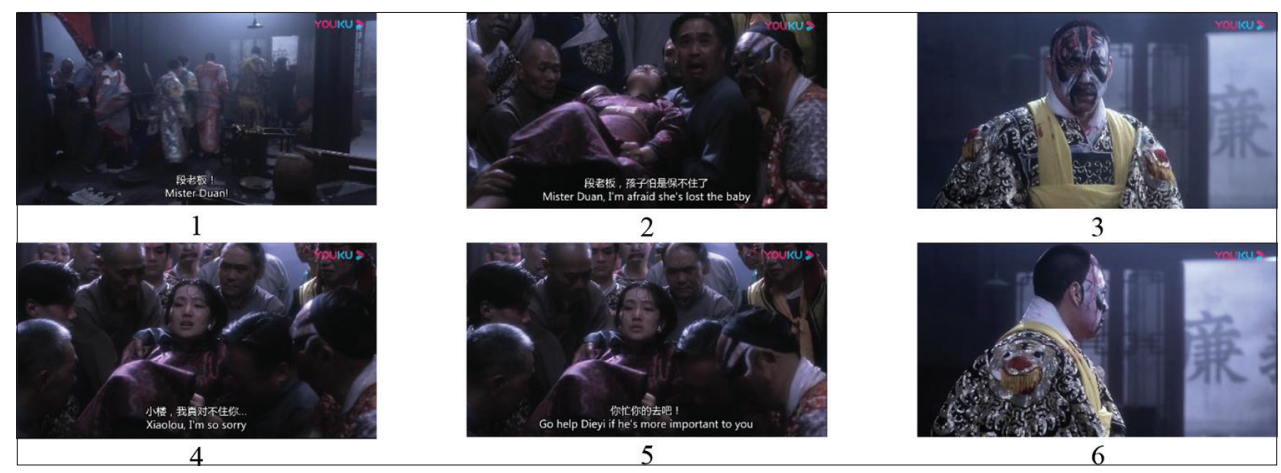

Figure 1. Xiaolou caught in dilemma

there seems a contrasted framing between Xiaolou and the background as the presence of faming "signifies individuality and differentiation" (Kress and van Leeuwen, 2006: 203). Though he acted as a hero, the King of Chu, he was powerless to save Xiaolou and his wife, Juxian. Juxian's seeming apology embodied her distress and indignation. She was too exhausted to raise her tone to reproach his husband who had promised not to perform the opera. The TT should have been "You can do as you need to do" while it is adapted to "Go help Dieyi if he's more important to you". The translated version emanates Juxian's jealousy and indignation, which contrasts with her facial expression that is calm and demure. The adaptation may not be the best choice but it does reflect the psychological activity of Juxian. In frame 6, Xiaolou was in such a dilemma as he merely saw the policemen leave but could not save anyone in the end. The adaptation in this example reveals Juxian's resentment that is not depicted in the form of languages but is based on Jaivin's understanding of the non-verbal modes. Thus, as a female translator, Javin also truly reflects the inward world of Juxian, an inconsolable woman.

In example 6, Jaivin changed what Dieyi said into the ideas that he dared not to clearly express. After Xiaolou solved the trouble of Juxian who was still a prostitute, Dieyi was at odds with Xiaolou. Dieyi confided his hopes to his "King of Chu" both in the performance and in reality. As Figure 2 shows, Dieyi scooted to Xiaolou. Dieyi's eyes were filled with admiration and "love" in frame 2 as if he had become Concubine Yu in that society. The close shot shows their tightly close distance which indicates their unusual intimate relationships. In frame 3, Dieyi suddenly realized that it was he that was Concubine $\mathrm{Yu}$ who must follow her King until her death. Jaivin noticed the information carried by visual modes, or else the subtitles would be like "I want to act in an opera the rest of my life". Actually, Dieyi had become Concubine Yu and had regarded Xiaolou as "her" king. What Dieyi really wanted was to be with Xiaolou the rest of "her" life like Concubine Yu. Jaivin's translation represents her ideology as her translation issues from the TT but goes beyond verbal modes.

\section{Amplification}

Constrained by the status and context, characters may not express fully their meaning which, however, can be detected by means of intersemiotic analysis or amplified by the translator's understanding of the audiovisual resources. The

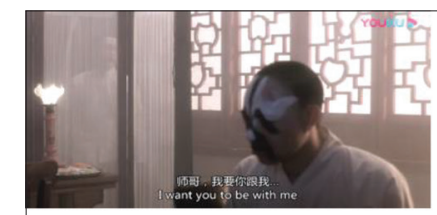

1

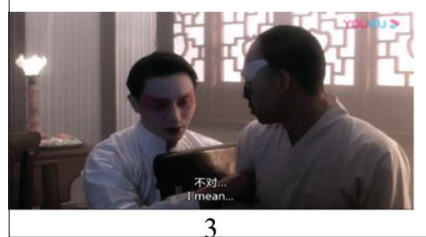

Figure 2. Dieyi's wishes to be with Xiaolou

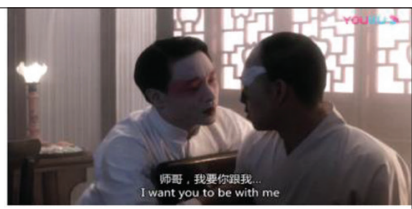

2

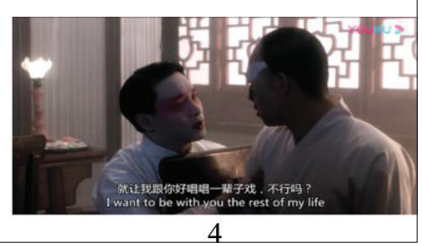

amplification is to make the unsaid manifest for cohesion as "when cohesion is given by the image, subtitles may jeopardise cohesive devices; the problem arises when cohesion needs to be reinforced through language for lack of visual redundancy" (Neves, 2009: 160).

In Figure 3, both frame 1 and frame 2 use a very close shot through which an intimate relationship is established between the interactive participants and represented participants. The gaze of Douzi's mother, a prostitute, is fairly impressive combined with her facial expressions. The contrast of discontinuities of color between the dominant hueblack and her head-pined flower separates the identity of prostitute from Douzi and his mother. The close shot presents her intended acting to viewers. Then, the shot turns long in frame 3 where the prostitute knelt down shamelessly with her head moving to one side and her hands on the leg. Mr. Guan stretched out hands to decline her demand and deny her statement. Then Mr. Guan pointed to himself with his thumb. His gesture directing both the woman and himself hints at their identity. Thus, the translation specifies and clarifies their identity instead of saying "humble professionals".

In the scene shown in Figure 4, Dieyi and Nakun talked across the screen. The acoustic modes in the scene include mew, blowing sound, burning sound and metallic sound. Doubtlessly, there is a cat in the scene though it is hard to find it because of the lighting and the coat color of the cat. Frame 4 proves the surmise. Associated with the previous scenes and the tobacco stem, it can be inferred that Dieyi was smoking the opium. In frame 3, Na Kun stood behind the folding screen, seeing clearly what happened to the cat. The mere frame 2 cannot judge what Dieyi was doing without the guidance of acoustic 
modes. The difficulties in understanding Dieyi's behavior make it indispensable to amplify the "blanks" that cannot be easily sensed especially for targeted viewers who are not cognizant of a certain context. The translated version "Lucky, the cat, wants you to blow more opium smoke at her" is a mental process where "lucky, the cat" is the Senser and "to blow more opium smoke at her" is Phenomenon. From the compositional meaning, in frame 1, the nearly invisible cat is given information while Dieyi is new information; in frame 4, the cat and Dieyi are given information. The information added, "the cat", reduces the viewers' cognitive burden or otherwise they will be busy associating visual images with subtitles.

\section{Non-translation}

The translation methods like deduction, adaptation and amplification are common in the subtitling as we have

Example 3

\begin{tabular}{|c|c|c|}
\hline \multicolumn{3}{|c|}{ Frame } \\
\hline ST & $\begin{array}{l}\text { 男怕《夜奔》, 女怕 } \\
\text { 《思凡》 }\end{array}$ & 那就来段《思凡》吧 \\
\hline TT & $\begin{array}{l}\text { "Dreaming of the } \\
\text { World Outside the } \\
\text { Nunnery" is the } \\
\text { hardest female role }\end{array}$ & Let's hear a bit of it \\
\hline
\end{tabular}

discussed above. However, Linda Jaivin, the translator of Farewell, My Concubine, deliberately omits some information most of which is related to stage performance and lyrics. "Non-translation", compared with "translation", is not translating. "Non-translation refers to the behavior that does not belong to translation. It includes code mixing, renaming, non-translation, rewriting and other processing means" (Tan, 2018: 104). The translator purposely avoids translating the original text as a translation strategy instead of considering the syntactic differences between TT and ST. However, non-translation in the subtitling of Farewell, My Concubine is not for "translation" or better interlingual exchanges, because non-translation mostly appears in opera lyrics that are elusive for both opera-lovers and foreign viewers. But instead, the non-translation signifies Jaivin's understanding of the culture and opera.

As Table 5 shows, the non-translation appears in six scenes when the represented participants perform opera or sing a song. The lyrics are not translated, some of which pinpoint that the "performers" are "performing" with subtitles like "Chattering", "BEIJING OPERA THE DRUNKEN CONCUBINE" and "Crowd Singing in Unison". The non-translation can be discussed from the perspective of multimodality. Five of six scenes relate to opera performance while the fifth scene is special as it is the Communist army who sang Military Song of People's Liberation Army of China after Dieyi and Xiaolou's performance failed. The song seems to be out of place in the theatre, which, however, contrasts with the behavior of the Kuomintang army who maliciously disturbed the performance as Figure 5 shows. However, it should be noted that there are translated subti-

Table 4. Multimodal transcription of Example 3

\begin{tabular}{|c|c|c|c|c|}
\hline Visual frame & Visual image & Kinetic action & Soundtrack & Subtitle \\
\hline & $\begin{array}{l}\text { CP static } \\
\text { HP frontal } \\
\text { D medium } \\
\text { VS Na Kun } \\
\text { VF Na Kun looking at the patio } \\
\text { stool }\end{array}$ & $\begin{array}{l}\text { Mr. Guan signaling } \\
\text { Na to sit down; } \mathrm{Na} \\
\text { doing as so }\end{array}$ & $\begin{array}{l}\text { Footstep; } \\
\text { wiping the bench } \\
\text { 男怕《夜奔》 }\end{array}$ & $\begin{array}{l}\text { "Dreaming of the } \\
\text { World Outside the } \\
\text { Nunnery" }\end{array}$ \\
\hline & $\begin{array}{l}\text { CP moving } \\
\text { VS Nakun } \\
\text { VF Na Kun watching Douzi }\end{array}$ & $\begin{array}{l}\text { Na Kun bending } \\
\text { his knees }\end{array}$ & 女怕《思凡》 & $\begin{array}{l}\text { is the hardest female } \\
\text { role }\end{array}$ \\
\hline & $\begin{array}{l}\text { CP static } \\
\text { VF Na Kun watching Douzi }\end{array}$ & $\begin{array}{l}\text { Na Kun sitting } \\
\text { down }\end{array}$ & 那就来段《思凡》吧 & Let's hear a bit of it \\
\hline & $\begin{array}{l}\text { VF focused } \\
\text { VS Shitou } \\
\text { D medium } \\
\text { VC Douzi's other stage brothers }\end{array}$ & $\begin{array}{l}\text { Shitou and others } \\
\text { stopping their } \\
\text { practice and } \\
\text { worring }\end{array}$ & & \\
\hline & $\begin{array}{l}\text { CP static } \\
\text { HP frontal } \\
\text { VF Douzi } \\
\text { VS Douzi's stage brothers } \\
\text { D close }\end{array}$ & Douzi performing & 小尼姑年方二八 & $\begin{array}{l}\text { At sixteen I am a } \\
\text { nun... }\end{array}$ \\
\hline
\end{tabular}


tles. So, why the performing scenes in Table 5 are devoid of subtitling while the performance in Figure 5 is not?

The flags in the theater in Figure 5 represent the identity of the audiences. The dark circumstance stands in stark contrast with the light of flashlights. The light on Dieyi's face displays the audiences' rudeness and ignorance of opera. Dieyi tried to perform and make the lyrics clear. A part of translated lyrics is relatively audible. The Kuomintang army, the audiences, cannot appreciate the opera. But the performance is fraught with political hue against a certain

Example 4

\begin{tabular}{lll}
\hline Frame & ST & TT \\
\hline & & \\
& & \\
& & \\
& & \\
&
\end{tabular}

Example 5

\begin{tabular}{lll}
\hline Frame & ST & TT \\
\hline & $\begin{array}{l}\text { 就让我跟你唱 } \\
\text { 行辈子? }\end{array}$ & $\begin{array}{l}\text { I want to be with } \\
\text { you the rest of my } \\
\text { life }\end{array}$ \\
\hline
\end{tabular}

backdrop. Dieyi may want to perform well but his performance did not receive due respect and appreciation. When Dieyi performed at the presence of the communist party, the political overtones overwhelm. Dieyi performed for the audiences with little knowledge of opera who even sang their military songs in the theater. Though they were more disciplined than the Kuomintang army, their song may imply their contempt for the opera that issues from the old society.

The same is true of the frame 1 in Table 5. Though Juxian was just one of the audiences, she was also ignorant of opera

Example 6

\begin{tabular}{|c|c|c|}
\hline Frame & ST & TT \\
\hline$\frac{\sqrt{x}}{4 \sqrt{3}}$ & $\begin{array}{l}\text { 都是下九流, } \\
\text { 谁嫌弃谁呀? }\end{array}$ & $\begin{array}{l}\text { Prostitutes and actors } \\
\text { are equally despised } \\
\text { by society }\end{array}$ \\
\hline
\end{tabular}

Example 7

\begin{tabular}{|c|c|c|}
\hline Frame & ST & TT \\
\hline 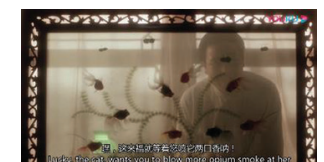 & $\begin{array}{l}\text { 嘿, 这来福就 } \\
\text { 等您喷它两口 } \\
\text { 香呐! }\end{array}$ & $\begin{array}{l}\text { Lucky, the cat, } \\
\text { wants you to blow } \\
\text { more opium smoke } \\
\text { at her }\end{array}$ \\
\hline
\end{tabular}

Table 5. Non-translation in each scene

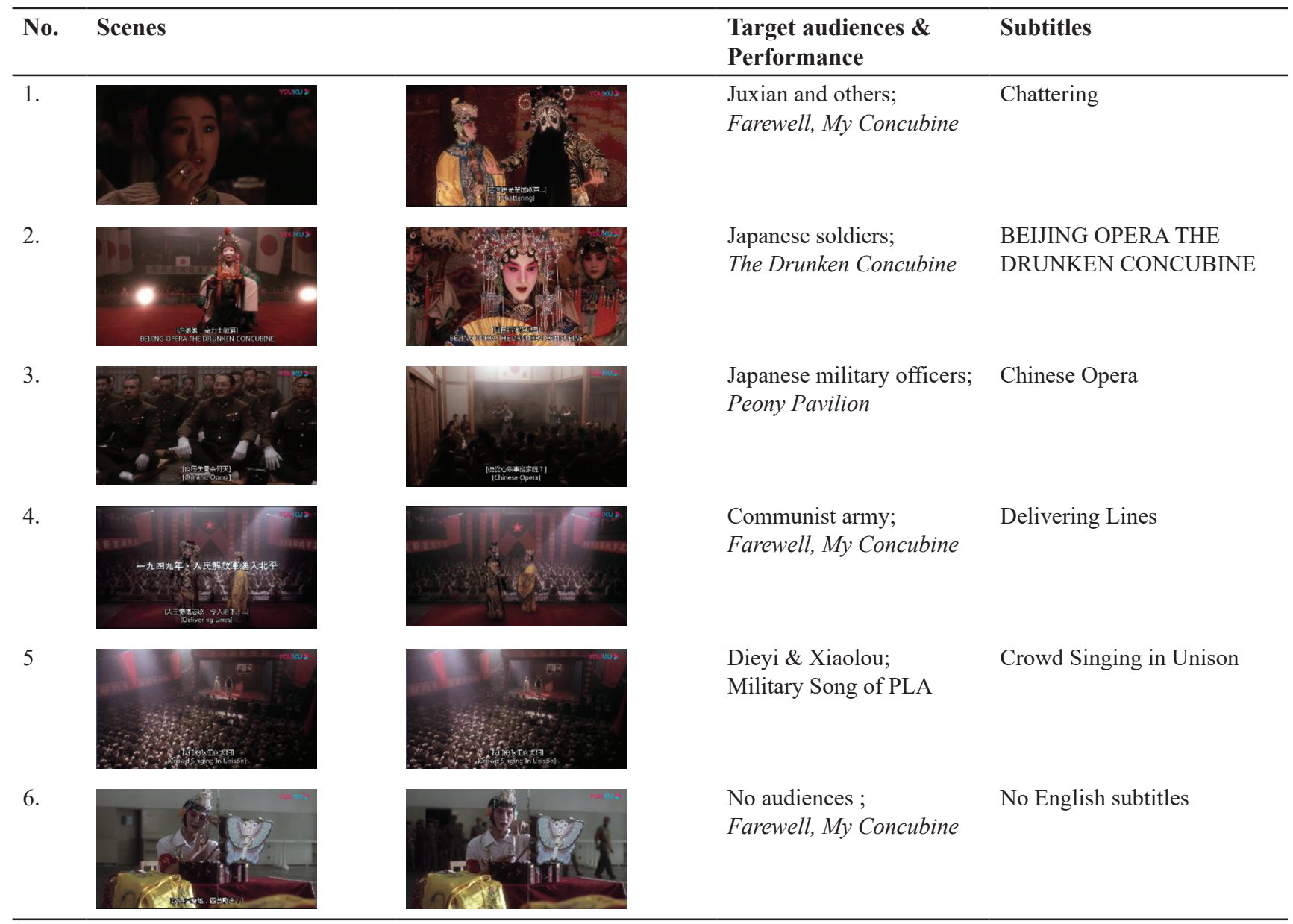


because she came to theater merely for Xiaolou. In frame 6, Xiaosi sang for himself and though he had learned the opera, he was still an ignorant one. Influenced by social conducts, he denied the traditional spirit of learning opera. His treachery signifies he was no longer a veritable performer but a fame-pursuer.

As for frame 2 and frame 3, most of the target audiences are Japanese in line with the setting. These audiences could appreciate the opera regardless of cultural and language differences. Thus, non-translation of lyrics means the art is universal.

In a nutshell, non-translation is adopted when the target audiences nearly know nothing about the art and cannot appreciate the opera, or when foreign audiences who really love the opera. Tan (2018: 106) believes that "non-translation" is for the sake of "translation" and better cross-cultural communication effect.

\section{INTERSEMIOTIC COMPLEMENTARITY}

The subtitling strategies have been analyzed from the perspective of multimodality. The methods involve deduction with condensation, reductive paraphrasing and dele-
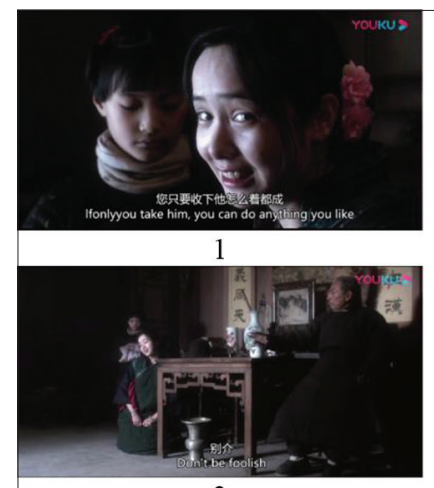

3
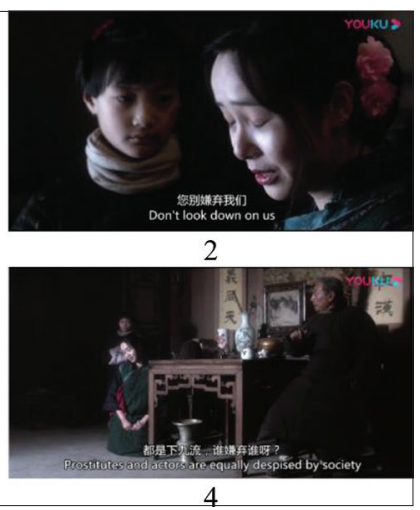

Figure 3. Douzi's mother imploring the headman

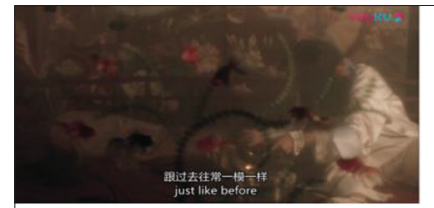

1

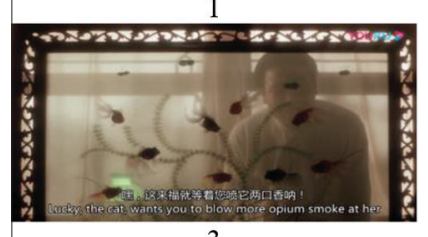

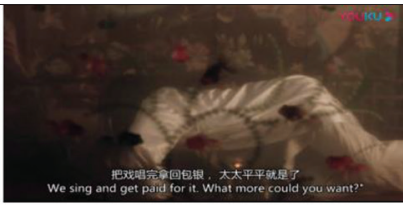

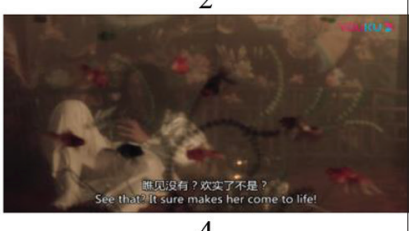

Figure 4. Dieyi taking opium tion involved, adaptation, a kind of reinterpretation in line with multimodality, amplification signifying the unsaid, and non-translation for conveying the translator's understanding of the art. Subtitling does not equate to the original subtitles though we may adopt linear translation which alters the original meaning as less as possible. However, translation itself will lead to a change of meaning. The change is more obvious as some methods are wielded such as deduction, adaptation and amplification. In this aspect, what is the relationship between verbal and non-verbal modes? Is there intersemiotic complementarity or dissonance? Moreover, if non-translation is adopted, what is the relation between the visual modes and verbal modes? Well, if Linda Jaivin does not subtitle at all, she does not alter the meaning of the ST, so we will not discuss the intersemiotic relation between translated subtitles and other semiotic modes. According to Royce (2002, 2007, 2015), intersemiotic complementarity can be used as a method for analyzing semiotic relations. In this section, the paper will concentrate on the ideational metafunction of verbal and non-verbal modes to figure out the relations between subtitles and non-verbal modes considering in some cases verbal and non-verbal modes carry varied information. Some meanings "can be expressed only visually, and some which can be expressed only through language" (Royce, 2015: 723). Besides, in some circumstances, subtitles and visual images tell different stories, which is called intersemiotic dissonance, "which is to account for cases where constituents of a multimodal text take different paths, in parallel with each other" (Yu, 2019: 2). This section will try to analyze the intersemiotic complementarity, focusing on the relations between Linda Jaivin's subtitles and other non-verbal modes.

\section{Deduction and Intersemiotic Complementarity}

The first case depicts that Douzi and Laizi fled from the troupe and encountered a celebrity in the carriages. The subtitles read "The stars have arrived! Here, come this way".

Ideational intersemiotic complementarity requires analyzers to center on questions around Identification, Activity and Circumstances together with the verbal elements. Identification refers to the questions like "Who or what are the represented participants (actor, recipient, goal)? Who or what are they interacting within the visual frame? Are the participants animate or inanimate, are they interacting (any interactional vectors?)" (ibid.)? The attributes mean "the qualities and characteristics of the participants" (Royce, 2007: 70). Then the paper moves to the activity by answering questions like "what action is taking place between the actor(s) and the recipient(s) or object(s) of that action? What is happening in terms of the events, portrayal, scene, states, types of behavior (gestures,
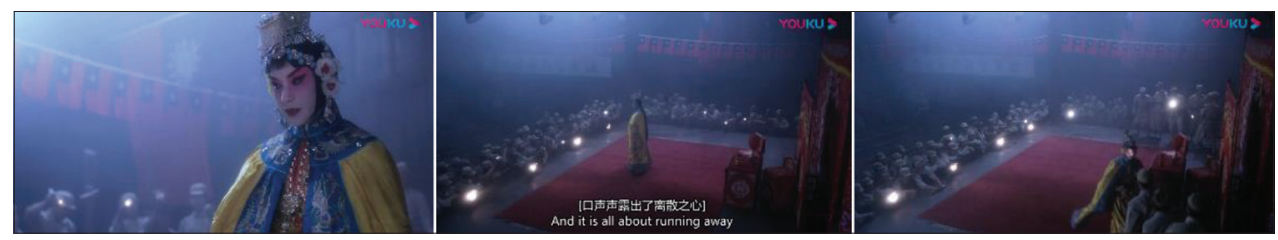

Figure 5. The performance for Kuomintang army 
facial expressions, stance, physical moves)?" (Royce, 2015: 729). Last, we should focus on the questions on Circumstances like "where, who with, and by what means are the activities being carried out (setting, means, accompaniment)?" (ibid.).

Then we should look at the subtitles "The stars have arrived! Here, come this way" in Figure 6. Based on what has been analyzed, the written text should be examined for lexical items that relate semantically to the VMEs. The choice of choosing lexical items is "based on the notion that the lexical items selected should be the closest semantically to each VME, or be reasonably expected to co-occur or collocate in a text drawn from that particular context of situation" (ibid.: 735). There, lexical cohesion is adopted to judge the intersemiotic relations which include Repetition, Synonymy, Antonymy, Meronymy, Hyponymy and Collocation. The analysis result is shown in Table 6 .

As Figure 7 shows, Douzi and Lazi determined to return. They met their master as soon as they arrived at the door. Facing master's fury, they have no choice but to flee again. The deleted

Table 6. Ideational analysis in figure 6

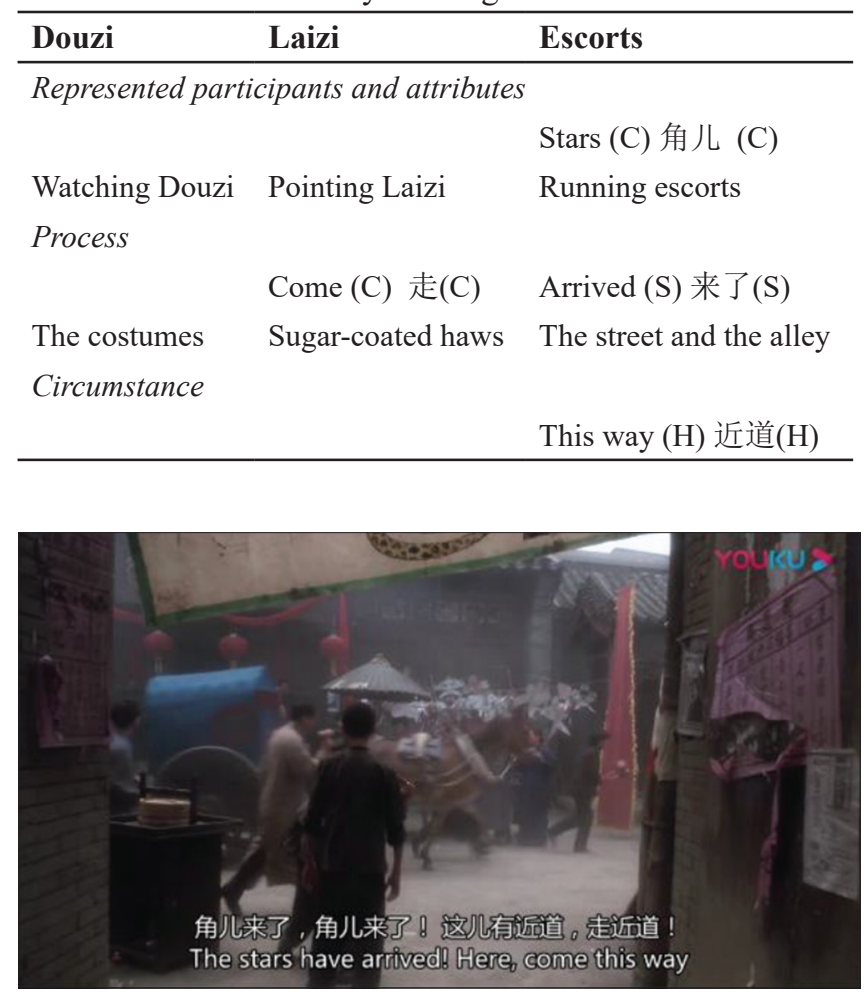

Figure 6. Encountering the opera star

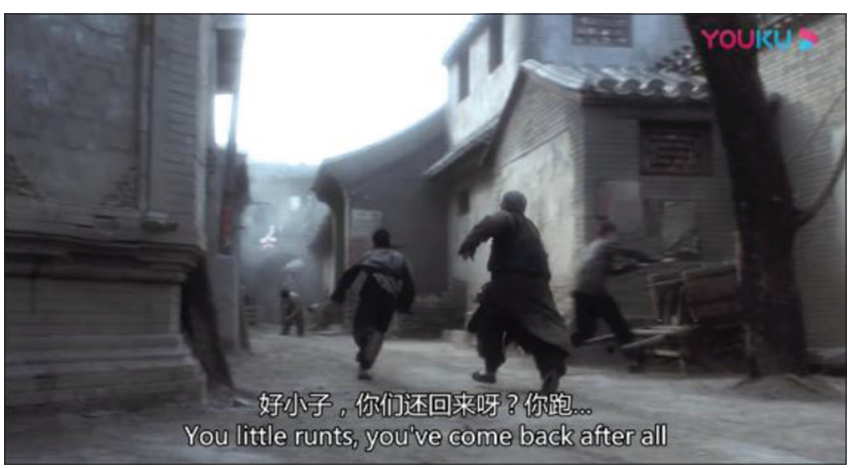

Figure 7. Fleeing from the punishment subtitles go "You little runts, you've come back after all" with the analyzed results in Table 7.

\section{Adaptation and Intersemiotic Complementarity}

Adapted subtitles are based on the translator's understanding of various modes that are composed of scenes as Table 8 and Figure 8 illustrate. The subtitles are "I want to be with you the rest of my life".

\section{Amplification and Intersemiotic Complementarity}

Though constrained by space and time, subtitling should not overly increase the burden of understanding. Some verbal elements thus should be added for foreign viewers as Figure 9 and Table 9 indicate.

In analyzing how semiotic modes interact ideationally, intersemiotic complementarity utilizes Halliday's SFG as well as the concepts and terminologies of lexical cohesion. From the analysis, it can be found that the concepts and terminologies of SFG do work to explain how semiotic systems work. Though the paper focuses on a limited number of case analysis, mainly concentrating on the processes, the results also indicate that Collation is most frequent in the realization of the complementary relations between visual and verbal modes. Collocation depends on a particular association between the items in question-a tendency to co-occur. This 'co-occurrence tendency' is known as collocation" (Halliday, 2014: 648). Besides, synonym is also common. In these cases, the synonym reflects the terms to address someone like "little runts", "prostitutes" and "actors". The relations like Hyponymy and Antonymy are less common.

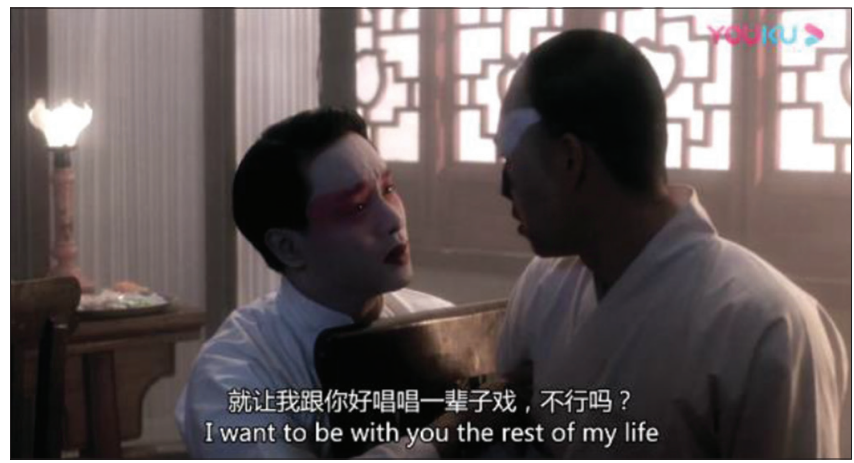

Figure 8. Dieyi confiding to Xiaolou

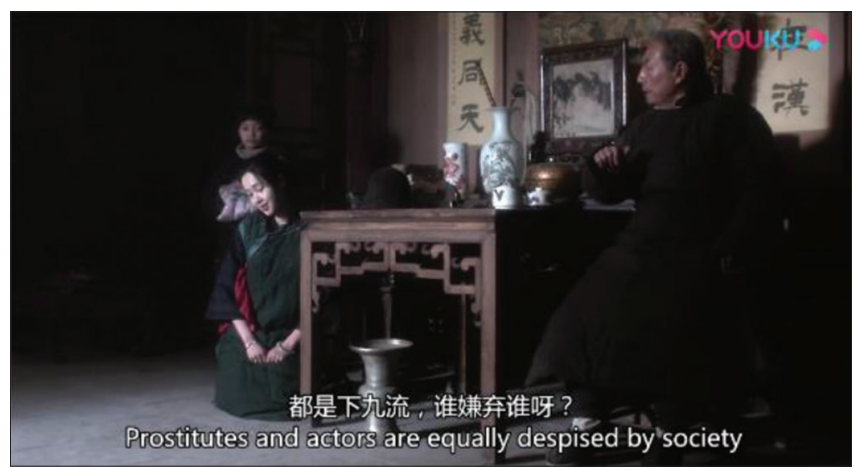

Figure 9. Douzi's mother kneeling down 
Table 7. Ideational analysis in figure 7

\begin{tabular}{|c|c|c|}
\hline Douzi & Laizi & Master \\
\hline \multicolumn{3}{|c|}{ Represented participants and attributes } \\
\hline \multicolumn{3}{|c|}{ little runts $(\mathrm{S})$ 好小子 $(\mathrm{S})$} \\
\hline Escaping Douzi & Escaping Laizi & Running master \\
\hline \multicolumn{3}{|l|}{ Process } \\
\hline \multicolumn{3}{|c|}{ Come back (A) 回来(A) 跑(S) } \\
\hline \multicolumn{3}{|l|}{ The alley } \\
\hline \multicolumn{3}{|l|}{ Circumstance } \\
\hline- & & \\
\hline
\end{tabular}

Table 8. Ideational analysis in figure 8

\begin{tabular}{ll}
\hline Dieyi & Xiaolou \\
\hline Represented participants and attributes & \\
- & \\
Confiding dieyi & Listening juxian \\
Process & \\
Want to be with you (C) 就让我和你唱一辈子(C) \\
Powder room \\
Circumstance \\
my life (C) 戏 $(\mathrm{C})$
\end{tabular}

Table 9. Ideational analysis in figure 9

\begin{tabular}{lcl}
\hline Mr. Guan & Douzi's mother & Douzi \\
\hline Represented participants and attributes & \\
Actors (S) & Prostitutes (S) 下九流(S) & \\
Denying man & Kneeling woman & Standing Douzi \\
Process & \\
嫌弃(S) & Despised (C) \\
Parlor & \\
Circumstance & \\
Society (H) & \\
\hline
\end{tabular}

Compared with the Chinese verbal elements as we have analyzed above, the English verbal elements generally function as the visual cohesion though the types of intersemiotic complementarity may be different from the Chinese elements. This indicates the changes in the Jaivin's subtitles are tied with ST and the interplay of semiotic modes. The Chinese subtitles narrate a similar story to avoid intersemiotic dissonance which will make it strenuous for audiences to look at both the subtitles and meanwhile comprehend the plot. These translation methods are the result of the particularity of audiovisual translation and the awareness of the significance of multimodality in translation.

Ideational intersemiotic complementarity is a feasible way to explore the relationships between the subtitles and images, and the theory is creatively adopted in dynamic text analysis to discuss the relations between subtitles and frames captured. Translation itself will lead to a change of meaning. The change is more obvious as some methods are wielded such as deduction, adaptation and amplification. Thus, it is not gratuitous to explore whether there is the antithesis of the subtitles between Chinese and English subtitles.

The analysis results prove that the intersemiotic complementarity can be used to explain the relations between visual and verbal modes by utilizing the concepts and terminologies in Halliday's SFG. In addition, the applicability also signifies the acceptability of Jaivin's subtitling which wields the translation methods that have changed the integrity or the content of information. Significantly, the expanded research perspectives facilitate the application of multimodality in the translation study.

\section{SUMMARY AND CONCLUSION}

First, the paper analyzes Linda Jaivin's subtitles by employing Taylor's idea of multimodal transcription. The analysis aims to probe into the translation adopted in her subtitles. Different translators may take varied measures to translate and may from various perspectives. Therefore, the analysis will be more intriguing to see how translated verbal modes interact with non-verbal modes. Furthermore, the relations between the ST and non-verbal modes differ from that between the TT and non-verbal modes because any kind of translation will definitely change the original meaning regardless of how hard the translator endeavors to retain the original information and style. With a view to proving the acceptability of Jaivin's translation, then, the paper further explores the relations between the verbal modes and non-verbal modes to see whether there is intersemiotic complementarity or not. The paper takes four cases as examples that cover all aspects of reduction, adaptation and amplification to illustrate how visual modes interact with verbal modes.

A question arises: do those subtitles that have been discussed in translation methods but not in the analysis of intersemiotic complementarity mean that the theory of intersemiotic complementarity is not applicable in the complementary analysis? It should be noted that what we are discussing here is the ideational intersemiotic complementarity, part of the theory intersemiotic complementarity. Ideational metafunction shall be realized through the clauses in TRANSITIVITY system. That means it is not appropriate for some ellipses short of integral syntactic structure to analyze their relations with visual modes. Significantly, what we are discussing there is mostly associated with the representational meaning in visual grammar. More exactly, it is the narrative processes in visual grammar that are being analyzed, and the elements like represented participants and attributes, processes and circumstances are taken into consideration. If we simply believe that verbal modes and non-verbal modes are complementary, to a large extent we are wrong because we need to consider the original ST to see whether ST is complementary with the non-verbal modes. Otherwise, the original subtitles narrate another story, which may influence the TT. Thus, the paper also takes the Chinese subtitles into consideration by analyzing their relations with non-verbal modes. In addition, even the modes are indeed complementary, complementary relations are by no means one kind. 
On the other hand, the translation methods that have been studied are far less frequent than other common methods like "transfer" according to Ghaemi's study (2011) that is based on Gottlieb's (1992) translation strategies. However, the translation methods that more or less change the ST deserve our attention given the spatial-temporal constraints, cohesion and target audiences because these methods reflect the translator's subjectivity based on Jaivin's understanding of semiotic modes.

Additionally, it should be noted that the paper takes the lead in the analysis of intersemiotic complementarity in subtitling. The film subtitle analysis differs from the static page-based analysis since the former is dynamic. Its changing modes make it difficult to attain the exact screenshots. However, the analysis has considered the dynamism of films by capturing the screenshots that are most representative and impressive in line with the frames and the interval of subtitles. Iedema (2001: 188-189) introduces six levels of analysis of films and televisions, and indicates "the frame is what the analyst takes to be the salient aspect of a shot" or "a frame is a salient or representative still of a shot". In this aspect, the screenshot captured can be regarded as the salient part that attracts viewers most. Thus, our analysis of a screenshot is well-founded.

It is found that multimodality is by no means a constraint on translation but serves an effective tool to figure out what is to be deducted, added or transformed. With the guidance of multimodal transcription, the paper identifies the methods of translating the film Farewell, My Concubine. These methods encompass deduction (with condensation, reductive paraphrasing and deletion included), adaptation, amplification and non-translation. Especially when these methods are adopted, translation itself will lead to a change of meaning. In this circumstance, ideational intersemiotic complementarity is a feasible way to explore the relations between the subtitles and images and is creatively adopted in dynamic text analysis to discuss the relations between subtitles and frames captured. The intersemiotic complementarity means the translation is advisable after the source text is analyzed to prove that there is no intersemiotic dissonance. There are two reasons for a multimodal approach. First, audiovisual translation cannot be separated from the participation of multimodality given the property of audiovisual products. Thus, the translation methods are explored by means of multiple modes. Second, as the paper has discussed, the theory of ideational intersemiotic complementarity derives from Systemic Functional Grammar and Visual Grammar, a theory which has been adopted to analyze the relationships between images and texts. That is, the cause and effect represented by translation methods and their acceptability are consistent as they are all discussed by means of multimodality. Besides, the complementary theory combines linguistic terminologies to make the analysis more objective and easier to make a judgement on the complementarity. The subtitles will promote the film development and the cross-cultural communication. From the analysis above, it can be sensed that a more simplified theory is entailed. Moreover, technical application in subtitling from the perspective of multimodality is preferred in the future study.

\section{REFERENCES}

Baldry, A. (2004). Phase and transition, type and instance: patterns in media texts as seen through a multimodal concordancer. In K. O'Halloran (Eds.), Multimodal Discourse Analysis: Systemic functional perspectives (pp. 83-108). London and New York: Continuum.

Bowcher W. L, Liang J. Y. (2013). Chinese tourist site entry tickets: Intersemiotic complementarity in an ecosocial process. Social Semiotics, 23(3): 385-408. https://doi.or $\mathrm{g} / 10.1080 / 10350330.2012 .738996$

Chaume F. (2004). Film studies and translation studies: Two disciplines at stake in audiovisual translation. Meta: journal des traducteurs/Meta: Translators' Journal, 49(1): 12-24. https://doi.org/10.7202/009016ar

Chuang Y. T. Studying subtitle translation from a multi-modal approach. Babel, 2006, 52(4):349-371. https://doi. org/10.1075/babel.52.4.06chu

Dollerup, C. (1974). On subtitles in television programmes. Babel, 0(4):197-202. https://doi.org/10.1075/babel.20.4.05dol

Gambier Y. (2006). Multimodality and audiovisual translation. MuTra 2006-Audiovsiual Scenarios: Conference Proceedings, 1-8. https://doi.org/10.1075/hts.4.mul2

Gambier, Y. (2013). The position of audiovisual translation studies. In C. Millán \& F. Bartrina (eds). The Routledge handbook of translation studies (pp. 63-77). Routledge. https://doi.org/10.4324/9780203102893.ch3

Ghaemi F., \& Benyamin J (2011). Strategies Used in the translation of interlingual subtitling. Journal of English Studies, 1: 39-49.

Gottlieb, H. (1992). Subtitling: A new university discipline. In C. Dollerup, et al. (Eds.), Teaching translation and interpreting (pp. 161-70). Amsterdam: John Benjamins. https://doi.org/10.1075/z.56.26got

Halliday, M. A. K, \& Christian M. (2014). Halliday’s Introduction to Functional Grammar. London: Routledge.

Iedema, R. (2001). Analysing film and television: A social semiotic account of hospital: An unhealthy business. In T. Van Leeuwen \& C. Jewitt (Eds.), Handbook of visual analysis (pp. 183-204), London: Sage Publications. https://doi.org/10.4135/9780857020062.n9

Jakobson, R. (1959). On Linguistic Aspects of Translation. In R. A. Brower (Eds.) On translation, (pp. 232-239). Cambridge: Harvard University Press. https://doi. org/10.4159/harvard.9780674731615.c18

Jin, H. (2013). From Farewell, My Concubine to The Grandmaster: An interview with Linda Jaivin, the film translator. Chinese Translators Journal, 34(04):65-67.

Kaindl, K. (2013). Multimodality and translation. In C. Millán, F. Bartrina (eds). The Routledge handbook of translation studies (pp. 275-288). Routledge. https://doi. org/10.4324/9780203102893.ch19

Kress, G., \& Theo Van Leeuwen (2006). Reading Images: The Grammar of Visual Design. London: Routledge.

Lau, J. K. W. (1995). "Farewell My Concubine": History, Melodrama, and Ideology in Contemporary Pan-Chinese Cinema. Film Quarterly, 16-27. https://doi. org/10.2307/1213489 
Leontovich, O. (2019). "A Sensible Image of the Infinite": Intersemiotic Translation of Russian Classics for Foreign Audiences. Russian Journal of Linguistics, (23): 399-414. https://doi.org/10.22363/2312-9182-2019-23-2-399-414

Li, Y. (2001). Strategies for Translating Subtitles. Chinese Translators Journal, (04), 38-40

Martinec, R., \& Salway, A. (2005). A system for image-text relations in new (and old) media. $\mathrm{Vi}$ sual communication, 4(3): 337-371. https://doi. org $/ 10.1177 / 1470357205055928$

Neves, J. (2009). Interlingual subtitling for the deaf and hard-of-hearing. In J. D. Cintas, G. Anderman (Eds.) Audiovisual Translation: Language transfer on screen (pp. 151-169). Palgrave Macmillan, London.

Pettit, Z. (2004). The audio-visual text: Subtitling and dubbing different genres. Meta: Journal des traducteurs/ Meta: Translators' Journal, 49(1): 25-38. https://doi. org/10.7202/009017ar

Royce, T. D. (2002). Multimodality in the TESOL classroom: Exploring visual-verbal synergy. TESOL quarterly, 36(2): 191-205. https://doi.org/10.2307/3588330

Royce, T. D. (2015). Intersemiotic Complementarity in Legal Cartoons: An Ideational Multimodal Analysis. International Journal for the Semiotics of Law-A Revue internationale de Sémiotique juridique, 28(4): 719-744. https://doi.org/10.1007/s11196-015-9421-1

Royce, T. D. (2007). Intersemiotic Complementarity: A Framework for Multimodal. In T.D. Royce, W. L. Bowcher (Eds.) New Directions in the Analysis of Multimodal Discourse (pp. 63-109). London: Lawrence Erlbaum Associates.

Shi, C., \& Han, Zh. (2018). A Comparative study of the overseas studies of Farewell, My Concubine between China and the West. Cultural Studies and Literary Theory, (01), 178188. http://dx.doi.org/10.13760/b.cnki.csalt.2018.0058

Tan, J. (2018). The Importance of Non-translation - A "Non-translation" strategy in Translation. Chinese Translation Journal, 39(05):102-108.
Tang, J. (2014). Translating Kung Fu Panda's kung fu-related elements: cultural representation in dubbing and subtitling. Perspectives, 22(3): 437-456. https://doi. org/10.4324/9781315228723-9

Taylor, C. (2003). Multimodal transcription in the analysis, translation and subtitling of Italian films. The translator, 9(2): 191-205. https://doi.org/10.1080/13556509.2003.1 0799153

Taylor, C. (2004). Multimodal text analysis and subtitling. Perspectives on multimodality, 153-172. https://doi. org/10.1075/ddcs.6.11tay

Taylor, C. (2015). Language as Access: Transposition and Translation of Audiovisual Texts as a Vehicle of Meaning and a Gateway to Understanding. In S. Starc, C. Jones \& A. Maiorani (Eds.) Meaning Making in Text (pp. 170-193). Palgrave Macmillan, London. https://doi. org/10.1057/9781137477309_10

Taylor, C. (2016). The multimodal approach in audiovisual translation. Target. International Journal of Translation Studies, 28(2): 222-236. https://doi. org/10.1075/target.28.2.04tay

Thibault, P. (2000). The Multimodal Transcription of a Television Advertisement: Theory and Practice. In A. Baldry (ed) Multimodality and Multimediality in the Distance Learning Age, Campobasso (pp. 311-385). Palladino Editore.

Yu, H. (2019). One page, two stories: intersemiotic dissonance in a comic adaptation of Journey to the West. Social Semiotics, 1-21. https://doi.org/10.1080/10350330. 2019.1645986

Zhou, J. (2011). Gender Temperament and its Historic Construction in Chen Kaige's Film Works. Modern Communication (Journal of Communication University of China), (12):163-164.

Zhu, Y. (2007). Theory and Methodology of Multimodal Discourse Analysis. Foreign Language Research, (05):82-86. http://dx.doi.org/10.16263/j.cnki.23-1071/h.2007.05.034

\section{NOTES}

Note 1. The whole film Farewell, My Concubine and its subtitles can be watched at https://v.youku.com/v_show/id XMzA1NTAzNjAwMA==.html?spm=a2h0k.11417342.soresults.dtitle\&s=cc00cce4962411de83b1 or https://www.youtube.com/watch? $\mathrm{v}=\mathrm{P} 9 \mathrm{n} 0 \mathrm{ro} 2 \mathrm{~d} 7 \mathrm{QE} \& \mathrm{t}=433 \mathrm{~s}$ (with no English subtitles)

Note 2. The dish "Farewell, My Concubine" made of turtle and hen is to mark the achievements of King of Chu who overrode the violent Qin Dynasty. The "turtle” in Chinese is “鳖” (“bie”), similar to the pronunciation of “别” representing the departure between King of Chu and Concubine Yu who is represented by "hen" in the dish that in Chinese is "鸡” (“ji”), similar to the pronunciation of “姬” (concubine). 